\title{
RISK INDICATORS AND RISK PREDICTORS OF DENTAL CARIES IN SCHOOLCHILDREN
}

\author{
Elaine Pereira da Silva TAGLIAFERRO', Gláucia Maria Bovi AMBROSANO², \\ Marcelo de Castro MENEGHIM ${ }^{3}$, Antonio Carlos PEREIRA ${ }^{4}$
}

\author{
1- DDS, MSc, Graduate student, Department of Community Dentistry, Faculty of Dentistry of Piracicaba, State University of Campinas, Piracicaba, \\ SP, Brazil. \\ 2- Agr.Eng., MSc, PhD, Professor, Department of Community Dentistry, Faculty of Dentistry of Piracicaba, State University of Campinas, Piracicaba, \\ SP, Brazil. \\ 3- DDS, MSc, PhD, Professor, Department of Community Dentistry, Faculty of Dentistry of Piracicaba, State University of Campinas, Piracicaba, SP, \\ Brazil. \\ 4- DDS, MPH, DrPH, Professor, Department of Community Dentistry, Faculty of Dentistry of Piracicaba, State University of Campinas, Piracicaba, \\ SP, Brazil.
}

Corresponding address: Prof. Dr. Antonio Carlos Pereira - Departamento de Odontologia Social - FOP/UNICAMP - Avenida Limeira, 901. Piracicaba, SP, Brazil - 13414-903 - e-mail: apereira@ fop.unicamp.br - Phone: 5519 2106-5209 - Fax: 5519 2106-5218

Received: October 11, 2007 - Modification: May 30, 2008 - Accepted: June 12, 2008

\begin{abstract}
$T_{\text {he }}$ he purpose of this study was to identify risk indicators of high caries level at baseline (HCLB) based on cross-sectional data and predictors of high caries increment (HCI) based on a 7-year-follow-up examination in 6-8-year-old schoolchildren. Two hundred and six schoolchildren were examined in 1997 and in 2004 by the same two calibrated dentists, in Piracicaba, Brazil. At baseline, dental caries, presence of sealants, fluorosis, and oral hygiene status were recorded. The children's parents completed a questionnaire concerning socioeconomic level, fluoride use, dental service utilization, dietary and oral hygiene habits. HCLB and HCI were defined considering the upper quartile of the total caries experience distribution (dmfs+DMFS) and caries increment distribution, respectively. Logistic regression models were adjusted estimating the Odds Ratio (OR), 95\% confidence intervals and p-values. Having white spot lesions $(\mathrm{OR}=5.25)$ was found to be a risk indicator of HCLB. Schoolchildren with dental fluorosis $(\mathrm{OR}=0.17)$ or those who brushed the teeth more than two times a day $(\mathrm{OR}=0.37)$ presented less probability of HCLB. The predictors of HCI were: $\mathrm{dmfs}>0(\mathrm{OR}=2.68)$ and mothers' educational level up to 8 years of schooling $(\mathrm{OR}=2.87)$. Clinical and socioeconomic variables were found to be risk indicators and/or predictors of dental caries in schoolchildren.
\end{abstract}

Key words: Dental caries. Prediction. Schoolchildren.

\section{INTRODUCTION}

Dental caries is a public health problem due to its widespread characteristic, cost of treatment and effects on the quality of life ${ }^{10}$. In spite of its decline observed in the last decades, high disease levels have still been identified in a minority of individuals, the so-called high-caries risk individuals. The early identification of these subjects allows health authorities to plan specific measures for caries prevention and to increase the efficiency of preventive programs. Several studies have been conducted in order to provide information on these high caries-level individuals. Not only clinical variables, but also socioeconomic and behavioral characteristics have been included in the studies on dental caries-related factors. The relevance of these studies lies on the fact that the knowledge of the main risk indicators and risk factors of the disease makes possible the identification of the individuals who would benefit from preventive measures.

When conducting a cross-sectional study, variables associated with dental caries are considered risk indicators, which might be risk factors of the disease ${ }^{3}$. Recent published studies have shown that caries experience in primary dentition, dental biofilm, presence of enamel defects, gender, educational level of mothers, socioeconomic status ${ }^{4}$, oral hygiene habits fluoride history, dental fluorosis ${ }^{12}$, access to oral health services, performance in school, sugar consumption, diet habits, area of residence ${ }^{5}$ are associated with caries in children and adolescents.

Caries-associated variables detected in longitudinal studies, in turn, are considered risk factors, which are environmental, behavioral or biologic factors that may directly increase, if present, or decrease, if removed, the probability of the occurrence of the disease ${ }^{3}$. Some longitudinal studies on caries risk assessment or caries prediction have included in their analysis only clinical 
variables ${ }^{18}$, whereas others have also assessed socioeconomic variables, fluoride history, dental service utilization, dietary and oral hygiene habits as caries predictors ${ }^{19}$. However, the outcome measure is always the caries increment, which can be dichotomized into any caries increment, selecting subjects who developed caries to any extent, or into high caries increment, selecting those with the highest DMFS increments. Studies on risk factors of high caries increment have demonstrated that baseline caries experience ${ }^{18}$, tooth morphology, lactobacillus score, white spot lesions ${ }^{1}$, oral hygiene habits, and sugar consumption ${ }^{19}$ have been significant caries predictors for European, North American or Chinese schoolchildren.

An important aspect is that caries risk indicators detected in cross-sectional studies could not always be confirmed as predictors/risk factors in longitudinal studies. Sometimes a variable associated with caries experience at the baseline examination presents no statistical relationship with caries increment in the same population.

The purpose of this study was to identify in 6-8-yearold schoolchildren the risk indicators of high caries level at baseline (HCLB) based on cross-sectional data, and the predictors of high caries increment (HCI) based on a 7-yearfollow-up examination.

\section{MATERIAL AND METHODS}

\section{Study Population}

The data for the present study were based on a research conducted in Brazilian schoolchildren between 1997 and $2004^{17}$. The sample size was determined considering a power test of 0.80 , a significance level of 0.05 and odds ratio of 2 . All 6-8-year-old children (mean age of 7.1 years) attending 3 different schools in the city of Piracicaba, SP, Brazil (mean fluoride concentration $=0.7 \mathrm{ppm}$ in drinking water, since 1971), with parents' consent, no systemic diseases or communication and/or neuromuscular problems, participated in this 7-year longitudinal study. A total of 480 children of both genders ( 251 boys and 229 girls) were examined at baseline, out of which, 350 returned a parental semi-structured questionnaire. In 2004, 206 individuals (13-16-year-old; mean age $=14.4$ years) were reexamined. All the children participated in a preventive program with placement of dental sealants in sound permanent teeth, regardless of their caries risk. Regarding socioeconomic variables, most fathers $(61.2 \%)$ and mothers (71.8\%) had attended school for 5 to 11 years and most families $(52.4 \%)$ received wages from 1 to 5 times the Brazilian minimum wage in 1997.

\section{Examination Methodology}

The dental examinations carried out in 1997 (baseline) and in 2004 (final examination) followed the same protocol. Two dentists participated in calibration sessions that included theoretical discussions and practical activities, before baseline and final examinations. Inter-examiner reliability and intraexaminer consistency were assessed in both surveys, reaching Kappa ${ }^{11}$ values higher than 0.85 for both examiners.
Prior to the examination, each individual received a toothbrush with fluoridated dentifrice and performed toothbrushing supervised by a dental hygienist. Then, the dentists examined the children under natural light in an outdoor setting, using mirror and dental probe that enabled them to remove residual dental plaque and detect pit-andfissure sealants. For data collection on dental caries, no radiographs were taken in either baseline or final examinations. Dental caries was registered using the $\mathrm{dmf}$ and DMF indexes according to the WHO codes and criteria ${ }^{20}$. In addition, initial lesions were also detected in dental surfaces according to Rimmer and Pitts ${ }^{14}$ (1991). Plaque score was measured using the Simplified Oral Hygiene Index ${ }^{7}$. The presence of dental fluorosis was examined in all teeth that showed more than $2 / 3$ of irrupted crown and no filling, using the Dean index ${ }^{6}$. The Russel's criteria ${ }^{15}$ were used for the differential diagnosis between very mild signs of dental fluorosis and nonfluorotic enamel opacities. The number of pit-and-fissure sealants was also recorded. At the final examination, the children were re-examined for dental caries and fluorosis status only.

\section{Collection of Non-Clinical Variables}

A semi-structured questionnaire was sent to the children's parents at baseline in order to collect data on socioeconomic level (parental educational level, number of working people in the household, monthly family income), use of fluoridecontaining products (use of topical preventive method), dental service utilization (number of and reasons for dental visits in the year prior to baseline), dietary (sugar consumption, between-meal snacks) and children's oral hygiene habits (toothbrushing frequency).

\section{Data Analysis}

Two dependent/response variables were defined based on the data used. The response variable from cross-sectional data was defined as 'HCLB' and the response variable from longitudinal data, as 'HCI'. The first was determined considering the upper quartile of the total caries experience distribution (dmfs+DMFS) at baseline, and the latter, considering the upper quartile of caries increment distribution after 7 years. Therefore, the schoolchildren with dmfs+DMFS $\geq 6$ presented high caries level and the individuals with a DMFS increment $\geq 4$ presented HCI. Univariate analyses (Chi-square or Fisher's exact tests) were performed to test the association between independent variables collected at baseline and the dependent variables separately. Only the independent variables with $\mathrm{p} \leq 0.15$ were selected for the regression analysis. By using the stepwise procedure, two regression models were constructed, one with HCLB as dependent variable, and the other with $\mathrm{HCI}$ as dependent variable. Adjusted odds ratios (OR), their $95 \%$ confidence intervals and significance levels were estimated. The variables that remained in the logistic regression model at $\mathrm{p}<0.05$ were considered as risk indicators, if the dependent variable was HCLB, or predictor if the dependent variable was HCI. All statistical tests were performed using the SAS software ${ }^{16}$ at $5 \%$ significance level. 


\section{Ethical Aspects}

The Research Ethics Committee of the Dental School of Piracicaba, State University of Campinas approved the study. A written permission from children's parents was obtained before starting the clinical examination.

\section{RESULTS}

Out of 480 children examined at baseline, 350 had completed questionnaire (response rate for questionnaire $=$ $72.9 \%$ ) and 206 could be reexamined (response rate for questionnaire + final examination $=42.9 \%$ ). Those lost to follow-up were due to school transfer or refusal to take part in the final examination. Caries prevalence of full participants at baseline was not significantly different $(\mathrm{p}=0.4$; Chi-square test) from those lost to follow-up. At baseline, $39.8 \%$ of the children were caries-free. On average each child presented 3.67 primary and permanent dental surfaces (dmfs+DMFS) with caries experience. A total of 56 children (27.2\%) were classified as high-caries level subjects (dmfs+DMFS $\geq 6$ ).

At the final examination, $51.5 \%$ of the individuals were caries-free; the mean (standard deviation) values for DMFT and DMFS were 2.16 (3.05) and 2.91 (4.29), respectively. The mean (standard deviation) DMFS increment was 2.63 (4.06), ranging from 0 (55.8\% of the children) to 19 dental surfaces $(0.5 \%$ of the children) over the 7 -year-period. At the final examination, 57 individuals $(27.7 \%$ ) exhibited HCI (new DMFS surfaces $\geq 4$ ).

The associations of independent variables with HCLB and HCI are shown in Table 1. The clinical variables (number of white spot lesions and dmfs) exhibited the strongest associations with either HCLB or HCI. Moreover, daily toothbrushing frequency and reasons for dental visits presented $\mathrm{p} \leq 0.15$ when in association with both HCLB and HCI.

In Table 2, the logistic regression model with HCLB as dependent variable show that the number of white spot lesions, dental fluorosis, and daily toothbrushing frequency remained in the final model at $\mathrm{p}<0.05$.

The variables that remained in the final model at $\mathrm{p}<0.05$ for HCI were dmfs and mother's educational level (Table 3). A higher risk of having a HCI was verified for children with caries in primary teeth $(\mathrm{OR}=2.68)$ or for those whose mothers' educational level went up to 8 years of schooling $(\mathrm{OR}=2.87)$.

TABLE 1- Association between independent variables and high caries level at baseline (HCLB) or high caries increment (HCl) at final examination

\begin{tabular}{|c|c|c|}
\hline Variable & HCLB* & $\mathrm{HCl}^{\star *}$ \\
\hline dmfs $(0 ;>0)$ & - & 0.0003 \\
\hline DMFS $(0 ;>0)$ & - & 0.1034 \\
\hline Number of white spot lesions - surface $(0 ;>0)$ & 0.0005 & 0.8064 \\
\hline Plaque score: mean OHIS $(\leq 1 ;>1)$ & 0.3426 & 0.6742 \\
\hline Number of dental sealants $(0 ;>0)$ & 0.7665 & 0.0663 \\
\hline Dental fluorosis (yes; no) & 0.0037 & 0.9986 \\
\hline Gender (male; female) & 0.0345 & 0.8186 \\
\hline Race (white; other) & 0.7101 & 0.0722 \\
\hline Mother's education ( $\leq 8 ;>8$ years of schooling) & 0.7516 & 0.0028 \\
\hline Father's education ( $\leq 8 ;>8$ years of schooling) & 0.6771 & 0.0770 \\
\hline $\begin{array}{l}\text { Number of working people living in the household }(0-1 ; 2 \text { or } \\
\text { more people) }\end{array}$ & 0.4196 & 0.4884 \\
\hline $\begin{array}{l}\text { Monthly family income - number in Brazilian minimum wages } \\
(\leq 5 ;>5 \text { minimum wages) }\end{array}$ & 0.0458 & 0.3774 \\
\hline Dental visits in the year prior to baseline (yes; no) & 0.2776 & 0.4973 \\
\hline $\begin{array}{l}\text { Number of dental visits in the year prior to baseline }(\leq 1 ;>1 \\
\text { visit) }\end{array}$ & 0.3299 & 0.7341 \\
\hline $\begin{array}{l}\text { Reason for dental visit (restorative care or routine visit; } \\
\text { extraction surgery or other reasons) }\end{array}$ & 0.014 & 0.0841 \\
\hline $\begin{array}{l}\text { Type of topical preventive method (mouth rinse or fluoride } \\
\text { gel; no method) }\end{array}$ & 0.7539 & 0.0651 \\
\hline Daily toothbrushing frequency ( $\leq$ twice; > twice a day) & 0.0049 & 0.0420 \\
\hline Daily sugar consumption ( $\leq$ twice; > twice a day) & 0.270 & 0.2048 \\
\hline Number of sugar spoons in beverages, etc ( $\leq 1 ;>1$ spoon) & 0.1622 & 0.7648 \\
\hline Number of between-meal snacks $(\leq 2 ;>2)$ & 0.9973 & 0.5961 \\
\hline
\end{tabular}

${ }^{*} \mathrm{dmfs}+\mathrm{DMFS}$ at baseline examination $\geq 6$. ${ }^{* *}$ DMFS increment at final examination $\geq 4$ 
TABLE 2- Multiple logistic regression analysis with high caries level at baseline (HCLB) as dependent variable

\begin{tabular}{|c|c|c|c|c|c|}
\hline \multirow[t]{3}{*}{ Variable } & \multirow{2}{*}{\multicolumn{2}{|c|}{$\begin{array}{c}\text { HCLB } \\
(\mathrm{dmfs}+\mathrm{DMFS} \geq 6)\end{array}$}} & \multirow{3}{*}{$\mathrm{OR}^{\star}$} & \multirow{3}{*}{${ }_{95 \%} \mathrm{Cl}^{\star *}$} & \multirow{3}{*}{$p$ value } \\
\hline & & & & & \\
\hline & $\mathbf{n}$ & $\%$ & & & \\
\hline \multicolumn{6}{|c|}{ Number of white spot lesions } \\
\hline 0 & 44 & 23.66 & 1.00 & & \\
\hline$>0$ & 12 & 60.00 & 5.25 & $1.59-17.29$ & 0.0016 \\
\hline \multicolumn{6}{|c|}{ Dental fluorosis } \\
\hline No & 51 & 32.08 & 1.00 & & \\
\hline Yes & 5 & 10.64 & 0.17 & $0.06-0.52$ & 0.0022 \\
\hline \multicolumn{6}{|c|}{ Daily toothbrushing frequency } \\
\hline$\leq$ twice a day & 32 & 38.10 & 1.00 & & \\
\hline > twice a day & 24 & 20.17 & 0.37 & $0.17-0.78$ & 0.0019 \\
\hline
\end{tabular}

${ }^{*} \mathrm{OR}=$ odds ratio. ${ }^{* *}{ }_{95 \%} \mathrm{Cl}=95 \%$ confidence interval

TABLE 3- Multiple logistic regression analysis with high caries increment $(\mathrm{HCl})$ at final examination as dependent variable

\begin{tabular}{|c|c|c|c|c|c|}
\hline \multirow[t]{3}{*}{ Variable } & \multirow{2}{*}{\multicolumn{2}{|c|}{$\begin{array}{c}\mathrm{HCl} \\
(\mathrm{DMFS} \text { increment } \geq 4)\end{array}$}} & \multirow{3}{*}{$\mathrm{OR}^{*}$} & \multirow{3}{*}{${ }_{95 \%} \mathrm{Cl}^{\star *}$} & \multirow{3}{*}{$p$ value } \\
\hline & & & & & \\
\hline & $\mathbf{n}$ & $\%$ & & & \\
\hline \multicolumn{6}{|l|}{ dmfs } \\
\hline 0 & 13 & 14.61 & 1.00 & & \\
\hline$>0$ & 44 & 37.61 & 2.68 & $1.27-5.65$ & 0.0007 \\
\hline \multicolumn{6}{|l|}{ Mother's education } \\
\hline$>8$ years of schooling & 15 & 16.85 & 1.00 & & \\
\hline$\leq 8$ years of schooling & 41 & 35.65 & 2.87 & $1.40-5.88$ & 0.0031 \\
\hline
\end{tabular}

${ }^{*} \mathrm{OR}=$ odds ratio. ${ }^{* *}{ }_{95 \%} \mathrm{Cl}=95 \%$ confidence interval

\section{DISCUSSION}

Due to the heterogeneous distribution of dental caries, interest in identifying caries-risk individuals has increased ${ }^{13}$. Risk indicators of caries in children have been widely investigated in cross-sectional studies over the years. Caries prediction has also been the topic of several longitudinal studies, showing past caries experience as the most powerful predictor of the disease ${ }^{18,19}$.

In the present study clinical, demographic, socioeconomic, fluoride history, and dental care service utilization variables were tested for association with HCLB and for HCI. The authors considered $15 \%$ significance level as the limit for a variable enter to the multiple logistic regression analysis, thus, eliminating those that would make little contribution to the model.

For HCLB as a dependent variable, the number of white spot lesions, dental fluorosis, and daily toothbrushing frequency were considered as risk indicators (Table 2). The children who presented one or more white spot lesions at baseline were more than 5 times likely to have high caries level at that moment. Other researchers have found caries experience in primary dentition as a risk indicator of the disease in permanent teeth ${ }^{4}$.

Another finding is that those with dental fluorosis were less prone to have a high caries level. Fluoride has been added to the water supply at an optimal level $(0.7 \mathrm{ppmF})$ in Piracicaba since 1971, and fluoridated dentifrices have been marketed in Brazil since 1989. The children from this study were born between 1989 and 1991, which indicates that they probably had access to both preventive methods.

The variable related to oral hygiene habits has also remained in the regression model, being considered a protector factor for HCLB. The schoolchildren who brushed the teeth more than two times a day were less prone to have a high caries level. It is important to observe that daily toothbrushing frequency was associated with both, HCLB (cross-sectional data) and $\mathrm{HCI}$ (longitudinal data) at $\mathrm{p}<0.05$ in the univariate analysis (Table 1). It means that this variable plays an important role in selecting people who will be at risk of 
developing caries. However, it has not reached statistical significance in the final model with HCI as a dependent variable, probably due to the strongest association between dmfs (past caries experience) and HCI. In fact, as reported by Hausen ${ }^{9}$, the past caries experience may give all the predictive power of a logistic regression function when including several other variables.

In the longitudinal analysis, with HCI as the dependent variable, multiple logistic regression analysis showed that dmfs and mother's educational level remained in the final model at $\mathrm{p}<0.05$ (Table 3 ). Children with caries in primary teeth at baseline were more likely to develop HCI over the 7year period, showing consistency with the findings of other studies $^{17,18}$. These findings and those reported in literature clearly indicate that caries experience in primary teeth is a good predictor of dental caries. The detection of caries experience at baseline suggests that the unbalanced deremineralization processes are frequently been occurring in the mouth. According to van Palenstein Helderman, et al. ${ }^{18}$ (2001), if oral health habits remain unchanged, caries activity can be expected in the future.

Low level of education of mothers was found to be a caries predictor, a finding that is in line with others ${ }^{8,17}$. The schoolchildren whose mothers presented up to 8 years of schooling exhibited higher chances of HCI. On the other hand, more than $80 \%$ of children whose mothers had higher education level at baseline ( $>8$ years of schooling) did not develop HCI. Mothers with insufficient understanding on oral health and caries prevention cannot adequately advise their children on, for instance, adequate toothbrushing and rational use of sugars. The authors suggest that schoolchildren with caries in primary teeth should be examined periodically for their oral health status and receive preventive care. Regarding the influence of mother's education, further research is necessary in other age groups in order to investigate this assumption.

Since this study has assessed risk indicators and risk predictors, findings from cross-sectional analysis were compared with longitudinal ones in order to evaluate which risk indicators could be confirmed as risk predictors. None of the studied variables remained in both regression models with either HCLB or HCI as dependent variables, indicating then that, in the present study, no risk indicator was confirmed as risk predictor of caries increment. Beck ${ }^{2}$ (1994), in a study of methods of assessing risk for periodontitis, has emphasized that risk indicators provided by cross-sectional data are frequently not confirmed as risk factors. On the other hand, supposed risk factors developed from longitudinal studies may be not evident in the prevalence data.

Two important aspects that should be discussed are that: (a) this study has demonstrated that individuals with white spot lesions were more likely to present HCLB, and (b) children with caries in primary dentition were more prone to develop HCI after 7 years (Tables 2 and 3). Although the variables are not exactly the same, they referred to the caries experience. Therefore, one can suggest that having teeth with caries experience at a cavitated or non-cavitated stage was the best caries predictor in this study.

\section{CONCLUSION}

Clinical and socioeconomic variables were found to be risk indicators and/or predictors of dental caries in schoolchildren.

\section{ACKNOWLEDGEMENTS}

The authors wish to thank the Principals of the schools for allowing the research carried out in 2004. Special thanks are due to Miss Lucilene Lins Alves for her assistance with the schoolchildren and MSc Cristiana Tengan, who contributed to this investigation. Acknowledgements to FAPESP (\#04/06033-9) and CAPES for financial support.

\section{REFERENCES}

1- Beck JD, Weintraub JA, Disney JA, Graves RC, Stamm JW, Kaste LM, et al. University of North Carolina caries risk assessment study: comparisons of high risk prediction, any risk prediction, and any risk etiologic models. Community Dent Oral Epidemiol. 1992;20:313-21.

2- Beck JD. Methods of assessing risk for periodontitis and developing multifactorial models. J Periodontol. 1994;65(5 Suppl):468-78.

3- Beck JD. Risk revisited. Community Dent Oral Epidemiol. 1998;26:220-5.

4- Casanova-Rosado AJ, Medina-Solís CE, Casanova-Rosado JF, VallejosSánchez AA, Maupomé G, Ávila-Burgos L. Dental caries and associated factors in Mexican schoolchildren aged 6-13 years. Acta Odontol Scand. 2005;63:245-51.

5- David J, Wang NJ, Åstrøm AN, Kuriakose S. Dental caries and associated factors in 12-year-old schoolchildren in Thiruvananthapuram, Kerala, India. Int J Paediatr Dent. 2005;15:420-8.

6- Dean HT. Classification of mottled enamel diagnosis. J Am Dent Assoc. 1934;21:1421-6.

7- Greene JC, Vermillion JR. The simplified oral hygiene index. J Am Dent Assoc. 1964;68:7-13.

8- Grindefjord M, Dahllof G, Nilsson B, Modeer T. Prediction of dental caries development in 1-year-old children. Caries Res. 1995;29:343-8.

9- Hausen H. Caries prediction: state of the art. Community Dent Oral Epidemiol. 1997;25:87-96.

10- Ismail A. Diagnostic levels in dental public health planning. Caries Res. 2004;38:199-203.

11- Landis JR, Koch GG. The measurement of observer agreement for categorical data. Biometrics. 1977;33:159-74.

12- Mascarenhas AK. Oral hygiene as a risk indicator of enamel and dentin caries. Community Dent Oral Epidemiol. 1998;26:331-9.

13- Powell LV. Caries prediction: a review of the literature. Community Dent Oral Epidemiol. 1998;26:361-71.

14- Rimmer PA, Pitts NB. Effects of diagnostic threshold and overlapped approximal surfaces on reported caries status. Community Dent Oral Epidemiol. 1991;19:205-12. 
15- Russel AL. The differential diagnosis of fluoride and non-fluoride enamel opacities. J Public Health Dent. 1961;21:143-6.

16- SAS Institute Inc. SAS/STAT. Release 8.2. Guide for personal computers. Cary: SAS Institute; 2001.

17- Tagliaferro EPS, Pereira AC, Meneghim MC, Ambrosano GMB. Assessment of dental caries predictors in a seven-year longitudinal study. J Public Health Dent. 2006;66:169-73.

18- van Palenstein Helderman WH, Mulder J, van't Hof MA, Truin GJ Validation of a Swiss method of caries prediction in Dutch children. Community Dent Oral Epidemiol. 2001;29:341-5.

19- Vanobbergen J, Martens L, Lesaffre E, Bogaerts K, Declerck D. The value of a baseline caries risk assessment model in the primary dentition for the prediction of caries incidence in the permanent dentition. Caries Res. 2001;35:442-50.

20- World Health Organization. Oral Health Surveys. Basic Methods. 3rd ed. Geneva: WHO; 1987. 